\title{
Emergência e desenvolvimento inicial de sementes de Dimorphandra mollis Benth. em campo
}

\author{
SOUZA, M.F.1*; MARTINS, E.R. ${ }^{2}$; FERNANDES, L.A.2; NERE, P.S. ${ }^{3}$
}

${ }^{1}$ Centro de Agricultura Alternativa do Norte de Minas, CEP 39401-034, Montes Claros-Brasil. ${ }^{2}$ Universidade Federal de Minas Gerais, Instituto de Ciências Agrárias, CEP 39404-006, Montes Claros-Brasil. 3Instituto Federal do Norte de Minas - Campus Salinas, CEP 39560-000, Salinas-Brasil. *Autor para correspondência: Manoelcaa@gmail.com

\begin{abstract}
RESUMO: Dimorphandra mollis Benth. (Leguminosae-Caesalpinioideae) é uma espécie arbórea, encontrada no bioma Cerrado, utilizada na recuperação de áreas degradadas e na ornamentação. Dos frutos, extrai-se a rutina, um bioflavonoide utilizado na indústria farmacêutica, o qual atua na permeabilidade e na resistência dos vasos capilares. Esta pesquisa teve como objetivo verificar os efeitos do tipo de solo e de adubos sobre a emergência e o vigor da favad'anta semeada diretamente no campo. O delineamento experimental adotado foi em blocos ao acaso, em esquema fatorial $4 \times 2$ (quatro tipos de adubação e dois tipos de solo), com sete repetições de cinco sementes cada. Foram avaliadas as seguintes características: emergência, primeira contagem da emergência, índice de velocidade de emergência, altura e diâmetro da plântula. Não houve interação significativa entre os fatores, tipo de solo e adubos. Os melhores resultados para emergência e IVE são obtidos quando a semeadura é realizada em solo local. Palavras-chave: Cerrado. Adubação. Plantas Medicinais.
\end{abstract}

\begin{abstract}
Emergence and initial development of Dimorphandra mollis Benth seeds in the field. Dimorphandra moliis Benth. (Laguminosae - Caesalpinioideae) is a tree species found in Cerrado, useful in the recovery of areas and as an ornamental plant. Rutin, estractedfrom the fruit, is a bioflavonoid used in the pharmaceutical industry which acts on the permeability and resistance of capillaries. This study aimed to determine the effects of soil type and fertilizers on the emergence and vigor of fava-d'anta sown directly in field. The experimental design adopted was randomized blocks in factorial scheme $4 \times 2$ ( four types of fertilizer and two types of soil) with seven replications of five seeds each. We evaluated the following features: emergence, emergence first count, emergence speed index, seedling height and diameter. There was no significant interaction among factors, soil type and fertilizers. The best results for emergence and $\mathrm{ESI}$ (emergence rate index) are obtained when the seeds is sown in local soil.
\end{abstract}

Keywords: Cerrado. Fertilization. Medicinal Plants.

\section{INTRODUÇÃO}

Entre as espécies do cerrado com grande potencial de exploração econômica, destaca-se a Dimorphandra mollis Benth., conhecida como favad'anta, que é uma árvore com legumes carnosos, ricos em rutina, quercetina e ramnose. Esses flavonoides e o açúcar ramnose são utilizados pela indústria farmacêutica em grande escala, tendo maior importância a rutina. Gomes \& Gomes (2000) relataram que $50 \%$ da produção mundial de rutina é proveniente da fava-d'anta, sendo que apenas $60 \%$ da demanda mundial tem sido atendida, justificando a expansão do mercado e a preocupação com a integridade e a preservação da espécie, por constituir a maior fonte desse princípio ativo.

As sementes da fava-d'anta são ricas em galactomananos, polissacarídeos quimicamente idênticos à goma-guar. Essa goma é usada industrialmente como espessante de iogurtes e sorvetes, cápsulas de medicamentos, lubrificante de brocas para prospecção de petróleo e em invólucros de bananas de dinamite (Panegassi et al., 2000).

Como a fava-d'anta não é cultivada até o momento, tem sido explorada de forma extrativista. Estudos revelam que esse extrativismo constitui 
alternativa sócio-econômica para coletores e comerciantes. Entretanto, os procedimentos de coleta, em sua maioria danificam as plantas, existindo a necessidade de estudos, principalmente, no que se refere ao plantio da espécie (Nunes et al., 2012).

O crescimento de qualquer ser vivo depende da combinação entre a sua constituição genética e o meio ambiente que o cerca. Nas plantas, alguns fatores ambientais que influenciam no crescimento e entre eles está a qualidade química e física do solo (Felfili et al., 2001; Luttge \& Scarano, 2004).

Hartmann et al. (1997) relataram que o solo deve atender a certos requisitos de textura e de estrutura, bem como apresentar uma boa composição das fases sólida, líquida e gasosa, de modo a permitir um desempenho satisfatório das sementes. Enquanto um solo arenoso é pobre em nutrientes e propriedades coloidais, um solo argiloso apresenta maior quantidade de nutrientes.

A maioria das espécies nativas do cerrado é capaz de responder à adubação. Entretanto há diferenças entre as espécies nas respostas aos nutrientes individuais. Portanto, esta pesquisa teve como objetivo verificar os efeitos do tipo de solo e de adubos sobre a emergência e o desenvolvimento inicial da fava-d'anta semeada diretamente no campo.

\section{MATERIAL E MÉTODOS}

O trabalho foi desenvolvido em área de cerrado em regeneração, numa propriedade na Comunidade Rural de Olhos-d'água, localizada a 30 km do Instituto de Ciências Agrárias da Universidade Federal de Minas Gerais (ICA/UFMG), município de Montes Claros - MG, em dezembro de 2008. A comunidade pratica o extrativismo dos frutos da espécie como fonte alternativa de renda.

As sementes de fava-d'danta foram coletadas após a maturação fisiológica na safra de $2007 / 2008$. Antes da semeadura, foi realizada a escarificação mecânica das sementes, removendose o tegumento do lado oposto à micropila, em seguida foram imersas em água à temperatura ambiente por 24 horas e semeadas diretamente nas covas (Fernandes et al., 2008).

As covas foram abertas com o auxílio de uma cavadeira do tipo "boca de lobo", em solo arenoso de ocorrência da espécie, nas dimensões de $30 \times 30 \times 30 \mathrm{~cm}$, sendo o espaçamento de plantio $6 \times 4 \mathrm{~m}$.

Uma semana após a distribuição dos tratamentos foram semeadas cinco sementes por cova à profundidade de $4 \mathrm{~cm}$. $O$ cultivo foi realizado em plantio de sequeiro.

As amostras de solo e esterco foram analisadas no Laboratório de Solos do ICA/UFMG. O número de sementes que emergiu foi avaliado semanalmente, a partir do início do experimento, adotando-se como critério de emergência o surgimento dos cotilédones e hipocótilo. Foram avaliadas as seguintes características: emergência - correspondente à porcentagem total de sementes emergidas até o $30^{\circ}$ dia após a semeadura; primeira contagem de emergência - correspondente à porcentagem de sementes germinadas no $7^{\circ}$ dia após o início do teste; índice de velocidade de emergência (IVE) determinado de acordo com a fórmula apresentada por Maguire (1962); altura das plantas foi medida com o auxílio de uma régua graduada e diâmetro do caule verificado com paquímetro digital.

$O$ delineamento experimental foi o de blocos ao acaso, em esquema fatorial $4 \times 2$. Cada cova recebeu adubação de acordo com o tratamento a ser aplicado, conforme delineamento experimental descrito a seguir. Os tratamentos foram quatro tipos de adubação e dois tipos de solo, quanto à textura, com sete repetições, como se segue:

tratamento 1- solo local e 3 litros de esterco bovino de curral curtido; tratamento 2 - solo local e $19 \mathrm{~g}$ de fosfato natural reativo; tratamento 3 - solo local, 3 litros de esterco bovino de curral curtido e $19 \mathrm{~g}$ de fosfato natural reativo; tratamento 4 (testemunha) - solo local; tratamento 5 - solo argiloso de cerrado e 3 litros de esterco bovino de curral curtido; tratamento 6 - solo argiloso de cerrado e $19 \mathrm{~g}$ de fosfato natural; tratamento 7 - solo argiloso de cerrado, 3 litros de esterco bovino de curral curtido e $19 \mathrm{~g}$ de fosfato natural reativo; tratamento 8 - solo argiloso mais solo de cerrado.

Os valores em porcentagem foram transformados para arco-seno $\sqrt{X / 100}$ (Banzatto \& Kronka, 2006), em que x é a porcentagem de sementes emergidas, a análise estatística foi realizada com o programa SAEG e as médias comparadas pelo teste de Tukey a $5 \%$ de probabilidade.

\section{RESULTADOS E DISCUSSÃO}

$\mathrm{Na}$ análise do esterco, observou-se 2,5\% de $\mathrm{N}, 1,05 \%$ de $\mathrm{P}_{2} \mathrm{O}_{5}, 1,33 \%$ de $\mathrm{K}_{2} \mathrm{O}, 1,41 \%$ de $\mathrm{CaO}$ e $0,89 \%$ de $\mathrm{MgO}$. As análises dos dois tipos de solo utilizados nos experimento mostraram que ambos possuíam pH baixo (Tabela 1), que é uma das características dos solos do Cerrado. Segundo Malavolta \& Kliemann (1985), a vegetação nativa do cerrado cresce sobre solos ácidos, pobres em bases trocáveis, principalmente o cálcio.

O solo local apresentou teor de argila de $12 \%$, que o caracteriza como um solo arenoso. 0 solo dito argiloso apresentou $44 \%$ de argila, sendo

Rev. Bras. PI. Med., Campinas, v.18, n.1, p.186-190, 2016. 
caracterizado como argiloso.

A escolha de um solo argiloso como substrato para a emergência de $D$. mollis foi feita com vistas à maior retenção de umidade e, consequentemente, buscar um maior índice de emergência, pois o experimento foi realizado no período de chuvas na região, porém no sistema de sequeiro. No entanto, logo após a implantação do experimento, nos meses seguintes, houve um índice alto de precipitação, quando comparado com o normal da região, chegando a $380 \mathrm{~mm}$ no primeiro mês e a $300 \mathrm{~mm}$ no segundo mês. Assim, a umidade dos solos foi alta, o que pode ter afetado a emergência nesse tipo de solo, como descrito a seguir.

As diferenças foram observadas entre os dois solos para os nutrientes fósforo $(P)$, potássio $(\mathrm{K})$, cálcio $(\mathrm{Ca})$, magnésio $(\mathrm{Mg})$ e matéria orgânica (MO) (Tabela 1), sendo o solo de cerrado com textura argilosa com os maiores valores desses nutrientes, no entanto, para a emergência, as características químicas do solo pouco influenciam. Nessa fase as características físicas têm maior interferência no desenvolvimento da planta, pois a aeração, o teor de umidade, a porosidade, e a radiação luminosa podem determinar a qualidade de um solo, no que se refere ao uso desse como substrato.

Os resultados mostram que não houve interação significativa entre os fatores, tipo de solo e adubos, para a emergência de fava-d'anta no sistema de plantio direto (Tabela 2).

Os valores observados para as variáveis altura e diâmetro não diferiram estatisticamente em função da adubação (Tabela 3).

Em relação à porcentagem de emergência (Tabela 3), avaliada no $30^{\circ}$ dia após a semeadura, constatou-se que os melhores resultados foram obtidos quando a semeadura foi realizada em solo local, com média de $66 \%$. A diferença na textura dos solos influi na capacidade de retenção de água, no teor de matéria orgânica e na drenagem. Assim, a permeabilidade do solo tem relação direta com a emergência de plântulas, solos bem estruturados são necessários para uma boa penetração das raízes (Benvenuti, 2003).

Avaliando a emergência de plântulas de fruteiras nativas do cerrado, Naves et al. (1992) observaram $68 \%$ de emergência para

TABELA 1. Atributos do solo local (SL) e do solo argiloso (SA) utilizados na semeadura direta de fava-d'anta (Dimorphandra mollis Benth.) em Montes Claros - MG

\begin{tabular}{|c|c|c|c|c|c|c|c|c|c|}
\hline \multicolumn{10}{|c|}{ Atributos do Solo } \\
\hline Solo & $\mathrm{pH}$ & P-Me & P-rem & $\mathbf{K}$ & $\mathrm{Ca}$ & Mg & Al & $\mathrm{H}+\mathrm{Al}$ & SB \\
\hline & (agua) & $(\mathrm{mg}$ & $(\mathrm{mg}$ & (mg & (cmolc & (cmolc & (cmolc & (cmolc & (cmolc \\
\hline & & $\mathrm{kg}-1)$ & $L-1)$ & $\mathrm{kg}-1)$ & $d m-3)$ & $d m-3)$ & $\mathrm{dm}-3)$ & $\mathrm{dm}-3)$ & $d m-3)$ \\
\hline SA & 5,7 & 1,7 & 38,5 & 85 & 0,2 & 0,1 & 0,4 & 3,42 & 0,52 \\
\hline$\overline{S L}$ & 5,7 & 3,8 & 27,4 & 114 & 2,80 & 1,2 & 0,8 & 4,94 & 4,29 \\
\hline & $\mathbf{t}$ & $\mathbf{m}$ & $T$ & $\mathbf{V}$ & MO & AG & AF & Silte & Arg. \\
\hline & $(\mathrm{cm}$ & $(\%)$ & $\left(\mathrm{cmol}_{\mathrm{c}}\right.$ & $(\%)$ & (dag & (dag & (dag & (dag & (dag \\
\hline & $\left.\mathrm{Ol}_{c} \mathrm{dm}^{-3}\right)$ & & $\left.\mathrm{dm}^{-3}\right)$ & & $\left.\mathrm{kg}^{-1}\right)$ & $\left.\mathrm{kg}^{-1}\right)$ & $\left.\mathrm{kg}^{-1}\right)$ & $\left.\mathrm{kg}^{-1}\right)$ & $\left.\mathrm{kg}^{-1}\right)$ \\
\hline SA & 0,92 & 44 & 3,94 & 13 & 1,77 & 24 & 54 & 10 & 12 \\
\hline $\mathrm{SL}$ & 5,09 & 16 & 9,23 & 47 & 2,93 & 4,7 & 27,3 & 24 & 44 \\
\hline
\end{tabular}

$\mathrm{pH}=$ potencial hidrogeniônico, $\mathrm{P}-\mathrm{Me}=$ fósforo disponível pelo extrator de mehlich, $\mathrm{P}$-rem = fósforo remanescente, $\mathrm{K}=$ potássio, Ca $=\mathrm{Cálcio}$, $\mathrm{Mg}=$ magnésio, $\mathrm{Al}$ = alumínio, $\mathrm{H}+\mathrm{Al}=$ hidrogênio e alumínio, $\mathrm{SB}=$ saturação por base trocáveis, $\mathrm{t}=\mathrm{CTC}$ (capacidade de troca de cátions) efetiva, $\mathrm{m}=$ porcentagem de saturação por alumínio, $\mathrm{T}=\mathrm{CTC}$ (capacidade de troca de cátions) a pH 7,0, $\mathrm{V}=$ percentagem de saturação por bases da CTC (capacidade de troca de cátions) a pH 7,0, $\mathrm{MO}=$ matéria orgânica, $\mathrm{AG}=$ areia grossa, $\mathrm{AF}=$ área fina, $\mathrm{Arg}=$ argila .

TABELA 2. Resumo da análise de variância para as variáveis emergência (EMERG), primeira contagem de emergência (PCE), índice de velocidade de emergência (IVE), altura (ALT) e diâmetro (DIA) de plântulas de Dimorphandra mollis Benth em dois tipos de solo e em quatro tipos de adubação, em Montes Claros - MG

\begin{tabular}{llllll}
\hline \multirow{2}{*}{ Fatores } & \multicolumn{4}{l}{ Quadrados médios } & \\
\cline { 2 - 6 } & EMERG $(\%)^{1}$ & PCE $(\%)$ & IVE & ALT $(\mathrm{cm})$ & DIA $(\mathrm{mm})$ \\
\hline Tipo de solo & $19,7^{* *}$ & $6,6^{*}$ & $13,07^{* *}$ & 0,7 & 1,16 \\
Adubo & 2,02 & 1,3 & 1,65 & 0,69 & 1,08 \\
Tipo de solo X Adubo & 0,09 & 0,01 & 1,02 & 0,11 & 0,86 \\
CV $(\%)$ & 45,5 & 38,8 & 51 & 9,68 & 7,5 \\
\hline
\end{tabular}

*, ${ }^{* *}$-significativo a 5 e $1 \%$ de probabilidade, respectivamente, pelo teste F. 1 - Dados transformados para arco-seno $\sqrt{X / 100}$. CV: coeficiente de variação.

Rev. Bras. PI. Med., Campinas, v.18, n.1, p.186-190, 2016. 
TABELA 3. Valores médios para as variáveis emergência (EMERG), primeira contagem de emergência (PCE), índice de velocidade de emergência (IVE), altura (ALT) e diâmetro (DIA) de plântulas de Dimorphandra mollis Benth em dois tipos de solo e quatro tipos de adubação, em Montes Claros - MG

\begin{tabular}{lccccc}
\hline Tipos de solo & EMERG (\%) & PCE (\%) & IVE & ALT (cm) & DIA (mm) \\
\hline Local & $66 \mathrm{a}$ & $24,28 \mathrm{a}$ & $0,395 \mathrm{a}$ & $3,23 \mathrm{a}$ & $1,11 \mathrm{a}$ \\
Argiloso & $38 \mathrm{~b}$ & $16,42 \mathrm{~b}$ & $0,239 \mathrm{~b}$ & $2,21 \mathrm{a}$ & $0,76 \mathrm{a}$ \\
Adubos & & & & & \\
Esterco bovino & $47 \mathrm{a}$ & $17,14 \mathrm{a}$ & $0,270 \mathrm{a}$ & $3,23 \mathrm{a}$ & $0,88 \mathrm{a}$ \\
Fosfato & $61 \mathrm{a}$ & $22,85 \mathrm{a}$ & $0,359 \mathrm{a}$ & $3,26 \mathrm{a}$ & $1,16 \mathrm{a}$ \\
Esterco bovino+fosfato & $57 \mathrm{a}$ & $24,28 \mathrm{a}$ & $0,371 \mathrm{a}$ & $3,34 \mathrm{a}$ & $1,02 \mathrm{a}$ \\
Testemunha & $40 \mathrm{a}$ & $17,14 \mathrm{a}$ & $0,268 \mathrm{a}$ & $3,39 \mathrm{a}$ & $0,80 \mathrm{a}$ \\
\hline
\end{tabular}

Em cada coluna, para cada fator, médias seguidas de mesmas letras minúsculas não diferem entre si pelo teste de Tukey a até $5 \%$ de probabilidade. *: significativo $(\mathrm{P}<0,05){ }^{* *}$ : significativo $(\mathrm{P}<0,01)$. 1 - Dados transformados para arco-seno $\sqrt{X / 100}$.

o baru (Dipteryx alata). Bocchese et al. (2008) estudandoTabebuia heptaphylla observaram taxas de $15,84 \%$, em solo arenoso e $40,4 \%$, em solo argiloso. Vieira \& Laura (2008) observaram 49\% de emergência de $D$. mollis em área de cerrado. Nesta pesquisa o solo argiloso não favoreceu a emergência de $D$. mollis.

Para os dados da primeira contagem da emergência, realizada no $7^{\circ}$ dia após a semeadura, observou-se comportamento semelhante ao observado na emergência (Tabela 3 ).

O crescimento inicial da plântula ocorre devido aos produtos de hidrólise dos compostos de reserva, o que torna baixa a absorção de nutrientes externos. Assim, o efeito resultante da adição do fósforo neste experimento, talvez não esteja diretamente relacionado com a ação desse nutriente, mas com a interação entre o fósforo e algum outro elemento existente no solo ou nos tecidos das plantas.

A espécie $D$. mollis se desenvolve melhor em solos bem drenados é considerada tolerante a solos ácidos e à toxicidade do alumínio (Oliveira, 1992). Entretanto, Costa et al. (2007) verificaram que a espécie responde bem à adubação mineral. Fagundes et al. (2011) observaram que a germinação de $D$. mollis ocorre de melhor maneira em solo de cerrado arenoso. Entretanto, Oliveira (1992) verificou, em casas de vegetação, altas taxas de sobrevivência de $D$. mollis tanto em solo de cerrado quanto em solo de mata (argiloso) esterilizado $(100 \%)$ e taxas decrescentes em solo de mata sem esterilizar.

A textura de um solo pode influenciar positiva ou negativamente na emergência de algumas espécies, pois plantas adaptadas a um ambiente podem encontrar algo desfavorável à sua emergência, quando submetidas a outro. Para algumas espécies, solos que têm maior capacidade de retenção de umidade podem interferir no processo de emergência, pois o ambiente mais úmido pode contribuir para a proliferação de microorganismos.

\section{CONCLUSÃO}

O solo de cerrado arenoso permite maior emergência e IVE de sementes de fava-d'anta em semeadura direta. A adubação não influenciou a emergência.

Em relação ao desenvolvimento das plântulas, verificou-se que os resultados, baseados na altura e no diâmetro, não foram eficientes na indicação dos melhores tratamentos, uma vez que não apresentaram diferenças significativas entre si.

A adubação utilizada não afetou a emergência e o desenvolvimento inicial de $D$. mollis. Avaliações posteriores são necessárias para verificar o efeito da adubação em outros estágios do desenvolvimento.

\section{REFERÊNCIAS}

BANZATTO, D. A.; KRONKA, S. N. Experimentação agrícola. 4 ed. Jaboticabal: FUNEP, 2006. 237p.

BENVENUTI, S. Soil texture involvement in germination and emergence of buried seeds. Agronomy Journal, v.95, p.191-198, 2003.

BOCCHESE, R.A. et al. Efeito de diferentes tipos de solos na germinação de sementes de Tabebuia heptaphylla, em casa telada. Cerne, v.14, n.1, p.62-67, 2008.

COSTA, C.A. et al. Nutrição mineral da fava d'anta. Horticultura Brasileira v.25, p.024-028, 2007.

FAGUNDES, M. et al. A qualidade do solo afeta a germinação das sementes e o desenvolvimento das plântulas de Dimorphandra mollis Benth. (Leguminosae: Mimosoideae). Acta Botanica Brasilica, v.25, n.4, p.908-915, 2011.

FELFILI, J.M. et al. Desenvolvimento inicial de espécies de mata de galeria. In: RIBEIRO, J. F.; FONSECA, C. E. L.; SOUZA-SILVA, J. C. Cerrado: caracterização e recuperação de matas de galeria. Planaltina-DF: 
Embrapa cerrados, 2001. p.779-811.

FERNANDES, L.A. et al. Níveis de nitrogênio, fósforo e potássio para a produção de mudas de fava-d'anta (Dimorphandra mollis Benth). Revista Brasileira de Plantas Medicinais, v.10, n.1, p.94-99, 2008.

GOMES, L.J.; GOMES, M.A.O. Extrativismo e biodiversidade: o caso da fava-d'anta. Ciência Hoje, v.27, n.161, p.66-9, 2000

HARTMANN, H.T. et al. Plant propagation: principles and practices. 6. ed. New Jersey: Prentice Hall, 1997.

LUTTGE, U.; SCARANO, F.R. Ecophysiology. Revista Brasileira de Botânica, v.27, p.1-10, 2004.

MAGUIRE, J.D. Speed of germination-aid in selection and evaluation for seedlings emergence and vigor. Crop Science, v.2, n.1, p.176-177, 1962.

MALAVOLTA, E.: KLIEMANN, H.J. 1985. Desordens nutricionais no cerrado. Potafos, Piracicaba, São Paulo.

NAVES, R.V. et al. Avaliação da emergência de plântulas de espécies frutíferas nativas do cerrado goiano. Pesquisa Agropecuária Tropical (UFG), v.21/22, n.1, p.133-141, 1992.

NUNES, J.D. et al. O extrativismo da fava d'anta (Dimorphandra mollis Benth.) na região do Norte de Minas Gerais. Revista Brasileira de Plantas Medicinais, Botucatu, v.14, n.2, p.370-375, 2012.

OLIVEIRA, L.M.Q. Estudo comparativo do crescimento em Dimorphandra mollis Benth e Enterolobium contortisiliquum (Vell.) Morong. 1992. 239f. Tese (Doutorado em Ciências) Instituto de Biologia da Unicamp. Campinas.

PANEGASSI, V.R. et al. Potencial tecnológico do galactomanano de sementes de faveiro (Dimorphandra mollis) para uso na indústria de alimentos. Ciência e Tecnologia de Alimentos. v.20, n.3, p.406415, 2000.

VIEIRA, E.A.: LAURA, V.A. Emergência, crescimento e sobrevivência de plântulas de dimorphandra mollis benth. em área de cerrado. In: SIMPÓSIO NACIONAL SOBRE CERRADO, 9., SIMPÓSIO INTERNACIONAL DE SAVANAS TROPICAIS, 2., 2008, Brasília. Anais... Brasilia: EMBRAPA Cerrados, 2008. 